\title{
EUS-guided gastroenterostomy versus enteral stenting for gastric outlet obstruction: Systematic review and meta-analysis
}

\section{(ㄷ)(이우}

Authors

Saurabh Chandan ${ }^{1}$, Shahab R. Khan ${ }^{2}$, Babu P. Mohan ${ }^{3}$, Aun R. Shah ${ }^{4}$, Mohammad Bilal' ${ }^{5}$ Daryl Ramai ${ }^{6}$, Neil Bhogal ${ }^{4}$, Banreet Dhindsa ${ }^{4}$, Lena L. Kassab ${ }^{7}$, Shailendra Singh ${ }^{8}$, Suresh Ponnada ${ }^{9}$, Andrew K. Nguyen ${ }^{3}$, Stephanie McDonough ${ }^{3}$, Douglas G. Adler ${ }^{3}$

Institutions

1 Division of Gastroenterology, CHI Creighton University Medical Center, Omaha, Nebraska, United States

2 Section of Gastroenterology, Rush University Medical Center, Chicago, Illinois, USA.

3 Division of Gastroenterology and Hepatology, University of Utah School of Medicine, Salt Lake City, Utah, United States

4 Gastroenterology and Hepatology, University of Nebraska Medical Center, Omaha, Nebraska, Unites States

5 Division of Gastroenterology, Beth Israel Deaconess Medical Center, Harvard Medical School, Boston, Massachusetts, United States

6 Internal Medicine, The Brooklyn Hospital Center, New York, United States

7 Internal Medicine, Mayo Clinic, Rochester, Minnesota, United States

8 Department of Medicine, West Virginia University Charleston Division, Charleston, West Virginia, United States

9 Internal Medicine, Carilion Roanoke Memorial Hospital, Roanoke, Virginia, United States

submitted 18.9.2020

accepted after revision 27.11 .2020

Bibliography

Endoscopy International Open 2021; 09: E496-E504

DOI 10.1055/a-1341-0788

ISSN 2364-3722

(c) 2021. The Author(s).

This is an open access article published by Thieme under the terms of the Creative Commons Attribution-NonDerivative-NonCommercial License, permitting copying and reproduction so long as the original work is given appropriate credit. Contents may not be used for commecial purposes, or adapted, remixed, transformed or built upon. (https://creativecommons.org/licenses/by-nc-nd/4.0/)

Georg Thieme Verlag KG, Rüdigerstraße 14,

70469 Stuttgart, Germany

Corresponding author

Douglas G. Adler MD, FACG, AGAF, FASGE, Professor of Medicine, Director of Therapeutic Endoscopy, Director,
GI fellowship Program, Gastroenterology and Hepatology, University of Utah School of Medicine, Huntsman Cancer Center, 30N 1900E 4R118, Salt Lake City, Utah 84132, United States

Fax: +1-801-581-8007

Douglas.adler@hsc.utah.edu

\# Supplementary material is available under https://doi.org/10.1055/a-1341-0788

\section{ABTRACT}

Background and study aims Endoscopic and surgical techniques have been utilized for palliation of gastric outlet obstruction (GOO). Enteral stenting (ES) is an established technique with high clinical success and low morbidity rate. Endoscopic ultrasound-guided gastroenterostomy (EUS-GE) is a novel approach that aims to provide sustained palliation of GOO. We conducted a comprehensive review and meta-analysis to evaluate the effectiveness in terms of clinical and technical success, as well as the safety profile of EUS-GE and ES.

Methods We searched multiple databases from inception through July 2020 to identify studies that reported on safety and effectiveness of EUS-GE in comparison to ES. Pooled rates of technical success, clinical success, and adverse events (AEs) were calculated. Study heterogeneity was assessed using $12 \%$ and $95 \%$ confidence interval.

Results Five studies including 659 patients were included in our final analysis. Pooled rate of technical and clinical success for EUS-GE was 95.2\% (Cl 87.2-.98.3, $\left.\mathrm{I}^{2}=42\right)$ and $93.3 \%\left(\mathrm{Cl} 84.4-97.3, \mathrm{I}^{2}=59\right)$ while for ES it was $96.9 \%(\mathrm{Cl}$ 90.9-99, $\left.\mathrm{I}^{2}=64\right)$ and $85.6 \%\left(\mathrm{Cl} 73-92.9, \mathrm{I}^{2}=85\right)$, respectively. Pooled rate of re-intervention was significantly lower with EUS-GE i.e. 4\% (CI 1.8-8.7, $\left.\mathrm{I}^{2}=35\right)$ compared to ES, where it was $23.6 \%\left(\mathrm{Cl} 17.5-31, \mathrm{I}^{2}=35\right), \mathrm{p}=0.001$. Pooled rates of overall and major AEs were comparable between the two techniques.

Conclusion EUS-GE is comparable in terms of technical and clinical effectiveness and has a similar safety profile when compared to ES for palliation of GOO. 


\section{Introduction}

Gastric outlet obstruction (GOO) can result from a variety of benign and malignant diseases and often leads to nausea, vomiting, and poor oral intake and can preclude the oral delivery of medications. Malignant causes of GOO include gastric or duodenal cancer, ampullary cancer, pancreatic cancer, bile duct cancer, gallbladder cancer among others [1,2]. The onset of malignant GOO portends a poor prognosis, with patients having a median survival of 3-6 months [3]. On the other hand, benign causes of GOO include chronic pancreatitis with duodenal stenosis, recurrent acute pancreatitis, surgical anastomosis, peptic strictures of the pylorus and duodenum, and other etiologies [4].

Traditionally, open or laparoscopic surgical gastroenterostomy (S-GE) and enteral stenting (ES) using self-expandable metal stents (SEMS) have been the primary management options for both benign and malignant GOO. While S-GE achieves long term effectiveness, major limitations of this approach include prolonged recovery times delaying chemotherapy for malignancy-related obstructions, delayed gastric emptying and gastroparesis, increased risk for adverse events (AEs), as well as substantial procedure-associated costs and the challenges of performing surgery in patients who often have unresectable disease [5-7]. In patients with malignant GOO with concomitant biliary obstruction needing surgical intervention, SGE is often combined with choledochojejunostomy. (biliary bypass) which carries considerable morbidity and mortality [8,9]. Complications including post-operative ileus have been reported in over $50 \%$ of patients, leading to a prolonged hospital stay, often ranging from $14-24$ days $[1,10,11]$.

ES is a widely used alternative to surgery, with a high clinical success and low morbidity rate, however clinical course is often complicated due to the recurrent obstruction caused by either stent migration or tumor infiltration occurring in as many as 50 $\%$ patients at 6 months in patients who live this long [5, 12-15]. Endoscopic ultrasound guided gastroenterostomy or EUS-GE was first described by Fritscher-Ravens et al. in the early 2000s, but it was only after the availability of a bi-flanged lumen-apposing metal stent (LAMS) that the technique was clinically adopted. EUS-GE is a novel approach that can potentially provide sustained palliation of outlet obstruction while maintaining a minimally invasive endoscopic approach. The technique involves insertion of a LAMS under EUS and fluoroscopic guidance from the stomach to the small bowel distal to the obstruction. While several studies on EUS-GE have reported recovery of oral intake in $90 \%$ of patients, without the risk of tumor ingrowth and/or overgrowth, and avoiding the potential morbidity of surgery [16-20], it remains an evolving endoscopic technique in its early stages of development. Additionally, there is paucity of data comparing outcomes of EUS-GE to ES.

We conducted a comprehensive review and meta-analysis to evaluate the effectiveness in terms of clinical and technical success, as well as the safety profile of EUS-GE and ES. We hypothesized that EUS-GE and ES have comparable outcomes in terms of clinical effectiveness and safety profile.

\section{Methods}

\section{Search strategy}

The literature was searched by a medical librarian for studies reporting outcomes of EUS-GE compared to ES. Search strategy was created using a combination of keywords and standardized index terms. A systematic and detailed search was run in July 2020 in Ovid EBM Reviews, ClinicalTrials.gov, Ovid Embase $(1974+)$, Ovid Medline (1946+ including epub ahead of print, in-process \& other non-indexed citations), Scopus (1970+) and Web of Science $(1975+)$. Results were limited to English language manuscripts. All results were exported to Endnote where 142 obvious duplicates were removed leaving 187 citations. The full search strategy is available in Appendix-1. As the included studies were observational in design, the MOOSE (Meta-analyses Of Observational Studies in Epidemiology) Checklist was followed and is provided as Supplementary Appendix-2. PRISMA Flowchart for study selection and PRISMA checklists were followed and are provided as Appendix-3a\&b $[21,22]$. Reference lists of evaluated studies were examined to identify other studies of interest.

\section{Study selection}

In this meta-analysis, we only included studies that compared the clinical outcomes of EUS-GE and ES. Studies were included irrespective of whether they were published as full manuscripts or conference abstracts, performed in inpatient or outpatient setting, follow-up time, presence or absence of surgically altered anatomy, and country of origin as long as they provided the appropriate data needed for the analysis.

Our exclusion criteria were as follows: (1) studies reporting individually on EUS-GE [19,23-30] and EUS-GE compared to surgical gastroenterostomy [31-33] (2) case reports and case series studies, (2) studies with sample size < 10 patients, (3) studies performed in the pediatric population (Age $<18$ years), and (4) studies not published in English language. In cases of multiple publications from a single research group reporting on the same patient same cohort and/or overlapping cohorts, data from the most recent and/or most appropriate comprehensive report were retained. The retained studies were decided by two authors (MB, SC) based on the publication timing (most recent) and/ or the sample size of the study (largest). In situations, where a consensus could not be reached, overlapping studies were included in the final analysis and any potential effects were assessed by sensitivity analysis of the pooled outcomes by leaving out one study at a time.

\section{Data abstraction and quality assessment}

Data on study-related outcomes from the individual studies were abstracted independently onto a standardized form by at least two authors (MB, ARS). Authors SC, SRK, DR, NB cross-verified the collected data for possible errors and two authors (SC, SRK) did the quality scoring independently. The Newcastle-Ottawa scale for cohort studies was used to assess the quality of studies [34]. This quality score consisted of 8 questions, the details of which are provided in Supplementary Table 1. 


\section{Outcomes assessed}

The outcomes assessed were as followed:

1. Pooled rates of technical success (defined as proper stent positioning as determined via endoscopy and fluoroscopy or as reported by study authors).

2. Pooled rate of clinical success (defined as ability to tolerate oral intake without vomiting for 90 days following the procedure or as reported by study authors)

3. Pooled rate of reintervention (defined as need for performing a repeat procedure for palliation of symptoms)

4. Pooled rate of overall AEs

5. Pooled rate of major AEs (defined by the ASGE lexicon for endoscopic AEs and AE subtypes. [35]

\section{Statistical analysis}

We used meta-analysis techniques to calculate the pooled estimates in each case following the methods suggested by DerSimonian and Laird using the random-effects model [36]. When the incidence of an outcome was zero in a study, a continuity correction of 0.5 was added to the number of incident cases before statistical analysis [37].

We assessed heterogeneity between study-specific estimates by using Cochran Q statistical test for heterogeneity, $95 \%$ confidence interval $(\mathrm{Cl})$ and the $\mathrm{I}^{2}$ statistics [37-39]. In this, values of $<30 \%, 30 \%$ to $60 \%, 61 \%$ to $75 \%$, and $>75 \%$ were suggestive of low, moderate, substantial, and considerable heterogeneity, respectively. We assessed publication bias, qualitatively, by visual inspection of funnel plot and quantitatively, by the Egger test [40]. When publication bias was present, further statistics using the fail-Safe $\mathrm{N}$ test and Duval and Tweedie's "Trim and Fill" test was used to ascertain the impact of the bias [41]. Three levels of impact were reported based on the concordance between the reported results and the actual estimate if there were no bias. The impact was reported as minimal if both versions were estimated to be same, modest if effect size changed substantially but the final finding would still remain the same, and severe if basic final conclusion of the analysis is threatened by the bias [42].

Meta-regression analysis was attempted, when feasible, to study the effects of patient variables on the pooled outcomes. Knapp-Hartung two-tailed $P<0.05$ was considered statistically significant and $R^{2}$ value was calculated to study the goodnessof-fit. All analyses were performed using Comprehensive MetaAnalysis (CMA) software, version 3 (BioStat, Englewood, New Jersey, United States).

\section{Results}

\section{Search results and population characteristics}

A total of five studies, with 659 patients were included in the final analysis [43-47]. A schematic diagram demonstrating our study selection is illustrated in Supplementary Fig. 1. A total of 278 patients underwent EUS-GE and 381 patients underwent ES. There were 379 males and 280 females included in our analysis. While the etiology in majority of patients undergoing EUSGE and ES was malignant GOO, 5 patients had GOO secondary to chronic pancreatitis [45]. Mean age ranged from 62 years to
72.7 years. Length of stay (LOS) ranged from 7.4 to 11.3 days. Median follow up time ranged from 103-234 days for EUS-GE and 61 to 180 days for ES. Further details of location and etiology of GOO along with the population characteristics are described in $>$ Table 1 and $>$ Table 2.

\section{Characteristics and quality of included studies}

All the included cohort studies were retrospective in design. Three studies were published as abstracts [45-47], while two were published as full manuscripts. Two studies were conducted as single center experiences $[43,45]$, whereas the others were multi-center. Details of the technique used for performing EUS-GE was described in only two studies $[43,48]$. Based on the New-Castle Ottawa scoring system, 3 studies [46-48] were considered to be of high quality and 2 studies $[43,45]$ were considered to be of medium quality. There were no low-quality studies.

\section{Meta-analysis outcomes}

The pooled rate of technical success for EUS-GE was $95.2 \%(\mathrm{Cl}$ 87.2-.98.3, $\mathrm{I}^{2}=42$ ) and for ES was 96.9\% (Cl 90.9-99, $\left.\mathrm{I}^{2}=64\right)$. There was no statistically significant difference between the two, $P=0.6$ ( Fig. 1)

The pooled rate of clinical success for EUS-GE was $93.3 \%(\mathrm{Cl}$ 84.4-97.3, $\left.\mathrm{I}^{2}=59\right)$ and for ES was $85.6 \%\left(\mathrm{Cl} 73-92.9, \mathrm{I}^{2}=85\right)$. There was no statistically significant difference between the two, $P=0.2$ ( $>$ Fig. 2 ).

The pooled rate of reintervention with EUS-GE was $4 \%(\mathrm{Cl}$ $\left.1.8-8.7, \mathrm{I}^{2}=35\right)$ and for ES was $23.6 \%(\mathrm{Cl} 17.5-31,12=35)$. The difference between the two was statistically significant, $\mathrm{P}=0.001$ ( $\triangleright$ Fig. 3).

The pooled rate of overall AEs with EUS-GE was $10.7 \%(\mathrm{Cl}$ 4.3-24.5, $\left.\mathrm{I}^{2}=63\right)$ and with ES was $19.7 \%\left(\mathrm{Cl} 8.9-37.9, \mathrm{I}^{2}=92\right)$. The difference between the two was not statistically significant, $P=0.3$ (Supplementary Fig. 1).

The pooled rate of major AEs, per ASGE Lexicon, with EUS-GE was $3.7 \%\left(\mathrm{Cl} 0.8-9.3, \mathrm{I}^{2}=59\right)$ and with ES was $2.8 \%(\mathrm{Cl} 0.6-$ $\left.12.2,1^{2}=75\right)$. The difference between the two was not statistically significant, $P=0.8$ (Supplementary Fig. 2).

\section{Validation of meta-analysis results Sensitivity analysis}

To assess whether any one study had a dominant effect on the meta-analysis, we excluded one study at a time and analyzed its effect on the main summary estimate. In this analysis, no single study significantly affected the outcome or the heterogeneity.

\section{Heterogeneity}

We assessed dispersion of the calculated rates using the $\mathrm{I}^{2}$ percentage values and the values are reported with the pooled rates in $>$ Table 1 . Overall, moderate to considerable heterogeneity was noted across the analysis. This can potentially be explained by two factors. First, all of the included studies were retrospective in design with most being multi-center experiences. This likely resulted inter-operator variability influencing procedural outcomes. Second, in three studies $[43,45,48]$, the 


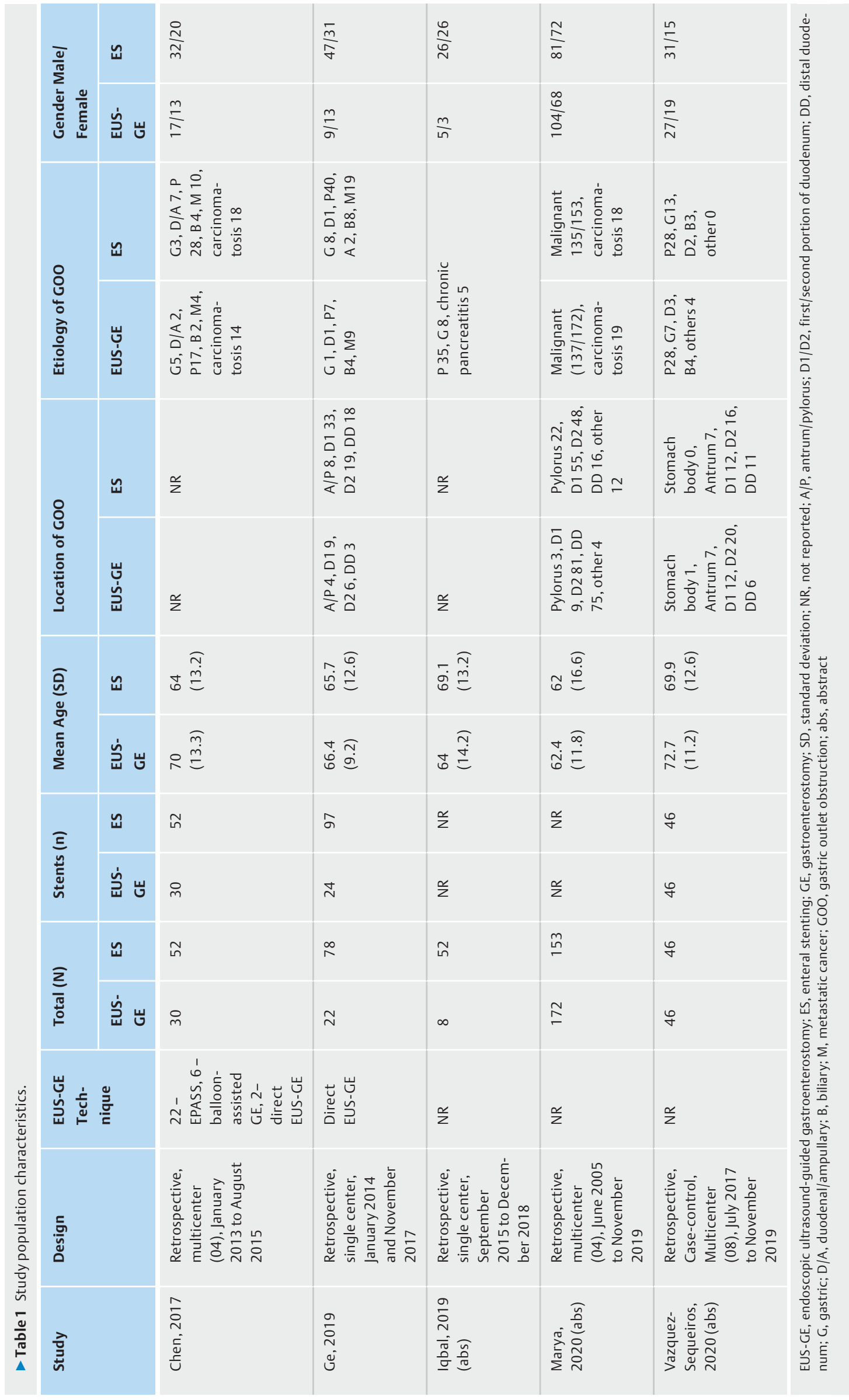




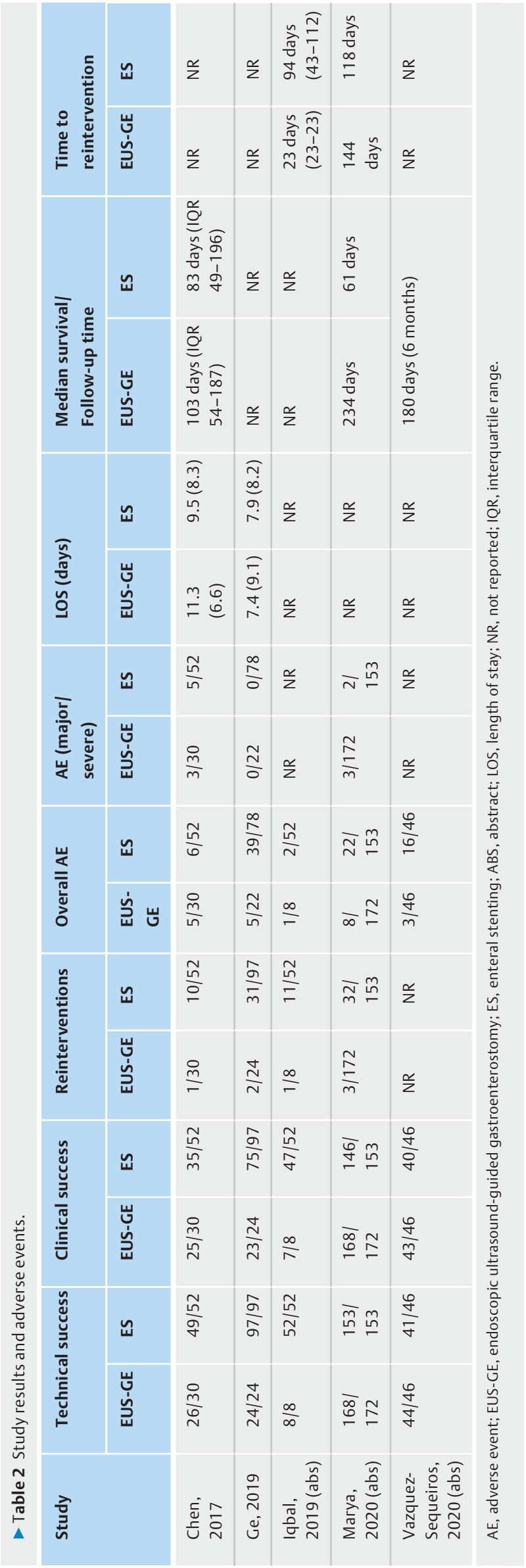

number of patients undergoing EUS-GE was significantly smaller than those undergoing ES.

\section{Publication bias}

Publication bias was not estimated as the number of studies included in the analysis was less than 10.

\section{Discussion}

Based on our meta-analysis, we conclude that EUS-GE is comparable to ES in terms of technical and clinical effectiveness. EUS-GE also has a similar safety profile. While the overall proportion of major AEs was higher in EUS-GE, the difference was not statistically significant. Our results also support the conclusion that EUS-GE is associated with a lower recurrence of GOO and need for re-intervention when compared to ES. To the best of our knowledge, this is the first meta-analysis comparing outcomes of EUS-GE and ES in patients with GOO in a large cohort of patients.

Endoscopic placement of self-expanding metal stents was first described in 1992 [49] and has been and remains widely utilized in the palliation of gastric outlet obstruction, most commonly due to malignancy. Studies have reported clinical success with ES to be between 75 and $90 \%$ depending on the definition of clinical success [50]. AEs including both immediate/early and late AEs have been reported in 10 to $40 \%$ in varies series [51]. While ES placement showed no statistically significant difference in terms clinical success, mortality, or complications when compared to S-GE, it has a shorter time to oral intake and length of survival [52]. With advances in interventional EUS techniques and the availability of LAMS, EUS-GE has emerged as a novel procedure. EUS-GE theoretically provides the same benefits as S-GE by allowing for a complete enteral bypass around the region of the obstruction, without the substantial morbidity and mortality associated with surgical intervention.

Our analysis showed that the overall pooled rate of AEs as well as major AEs was comparable between EUS-GE and ES. Chen et al reported a total of 11 AEs, 5 in EUS-GE group and 6 in ES group. These included misdeployment of the stent into the peritoneum $(n=3)$, abdominal pain requiring hospitalization $(n=2)$, pancreatitis $(n=2)$, cholangitis $(n=2)$ and perforation $(n=1)$. Ge et al reported that while patients with ES had a greater number of AEs (40.2\% vs. $20.8 \%$ ) and incidence of stent ingrowth ( $16.5 \%$ vs. $4.2 \%$ ) compared to the EUS-GE, the difference between the two groups was not statistically significant. Additional AEs occurring in the enteral stent group included stent obstruction (7.2\%), stent migration $(2.1 \%)$, inadequate stent length requiring repeat intervention (2.1\%), stent-related bleeding (1.0\%), and stent-related biliary obstruction $(2.1 \%)$. Vazquez-Sequeiros et al reported that while one patient each in the EUS-GE and ES groups had perforation, the incidence of stent dysfunction was significantly higher in the ES group (22\% vs $4 \%$ ). In our analysis, while the pooled rate of serious AEs was higher with EUS-GE than ES (3.7\% vs $2.8 \%$ ), the difference between the two was not statistically significant. Overall, when considering all AEs, EUS-GE and ES have a comparable safety 


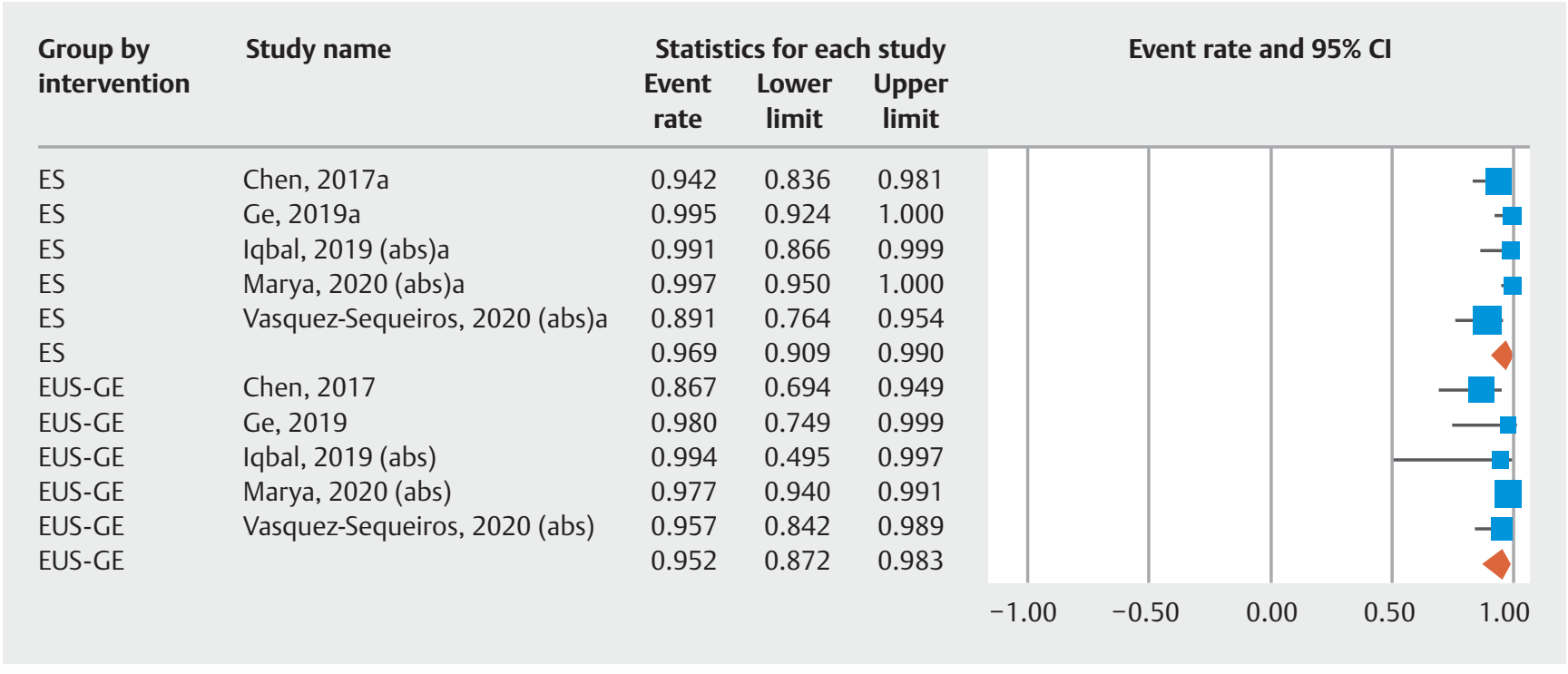

- Fig. 1 Forest plot of technical success.

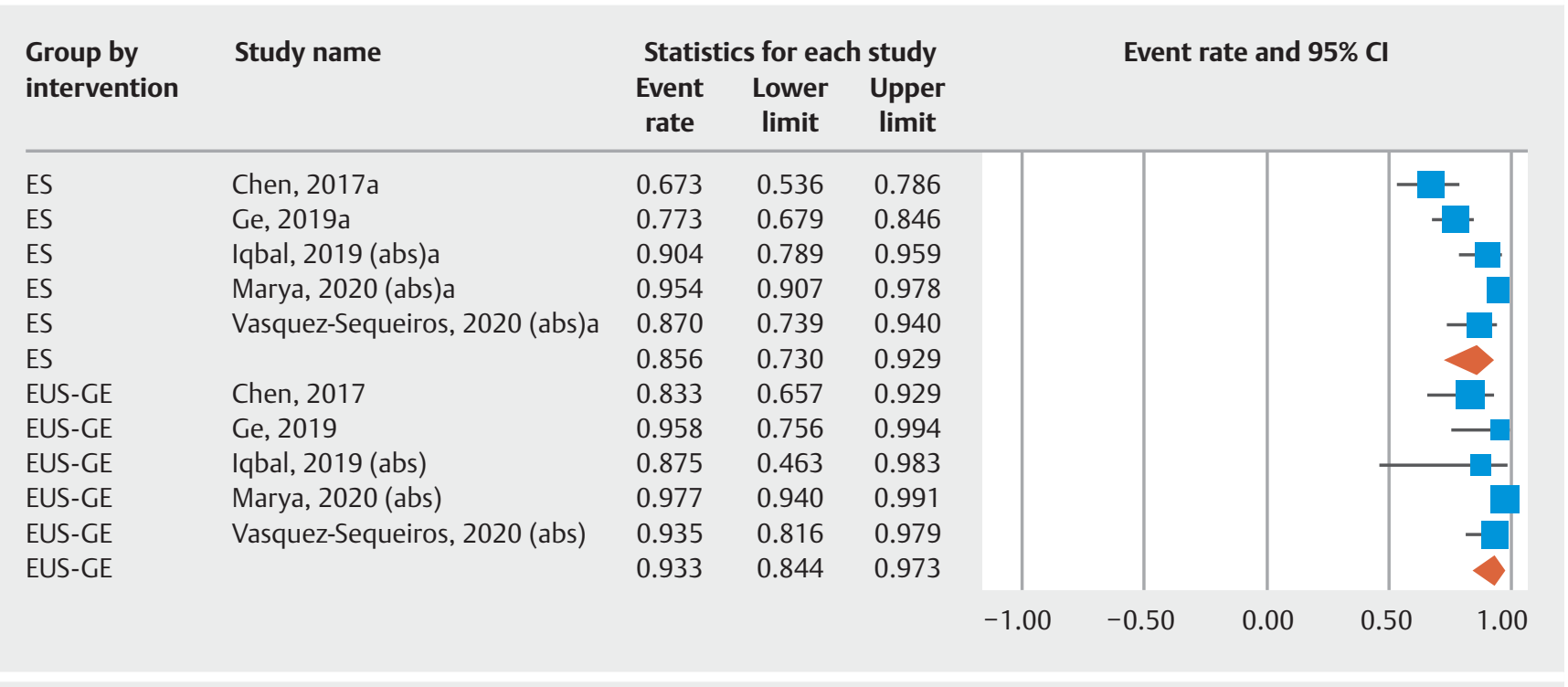

-Fig. 2 Forest plot of clinical success.

profile. ES is a simple, fast, and easy procedure which does not require the operator to have expertise in EUS. Two small randomized, controlled trials of ES versus laparoscopic gastrojejunostomy demonstrated effectiveness of both techniques, with fewer AEs and shorter hospital stay for patients who underwent enteral stenting $[53,54]$. EUS-GE, on the other hand, is a highend skill requiring more hardware and more experience and includes a perforation (albeit an iatrogenic one). It is important to recognize that all studies included in our review included EUS-GE performed at tertiary care centers with expert advanced endoscopists. Therefore, the AE rate might not be generalizable. Further studies will be needed to clarify this.

There are several strengths to our review: systematic literature search with well-defined inclusion criteria, careful exclusion of redundant studies, inclusion of good quality studies with detailed extraction of data and rigorous evaluation of study quality. All the included studies in our analysis reported outcomes of EUS-GE and ES, which allowed us to perform a comparative meta-analysis between the two techniques. Iqbal et al performed a separate systematic review and meta-analysis evaluating the safety and effectiveness of EUS-GE in GOO. While pooled technical and clinical success was achieved in $>90 \%$ of patients, this analysis included only 285 patients from 12 studies [55]. Similarly, two other studies also reported on the effectiveness of EUS-GE $[56,57]$. However, none of the aforementioned studies included a comparator intervention group such as ES. To the best of our knowledge, ours is the first and most comprehensive analysis evaluating outcomes of EUSGE as compared to ES. 


\begin{tabular}{|c|c|c|c|c|c|c|c|c|c|}
\hline \multirow{2}{*}{$\begin{array}{l}\text { Group by } \\
\text { intervention }\end{array}$} & \multirow[t]{2}{*}{ Study name } & \multicolumn{3}{|c|}{ Statistics for each study } & \multicolumn{5}{|c|}{ Event rate and $95 \% \mathrm{Cl}$} \\
\hline & & $\begin{array}{l}\text { Event } \\
\text { rate }\end{array}$ & $\begin{array}{l}\text { Lower } \\
\text { limit }\end{array}$ & $\begin{array}{l}\text { Upper } \\
\text { limit }\end{array}$ & & & & & \\
\hline ES & Chen, 2017a & 0.192 & 0.107 & 0.332 & & & & & \\
\hline ES & Ge, 2019a & 0.320 & 0.235 & 0.419 & & & & 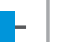 & \\
\hline ES & Iqbal, 2019 (abs)a & 0.212 & 0.121 & 0.343 & & & & & \\
\hline ES & Marya, 2020 (abs)a & 0.209 & 0.152 & 0.281 & & & & & \\
\hline ES & & 0.236 & 0.175 & 0.310 & & & & & \\
\hline EUS-GE & Chen, 2017 & 0.033 & 0.005 & 0.202 & & & & & \\
\hline EUS-GE & Ge, 2019 & 0.083 & 0.021 & 0.279 & & & - & & \\
\hline EUS-GE & Iqbal, 2019 (abs) & 0.125 & 0.017 & 0.537 & & & H & & \\
\hline EUS-GE & Marya, 2020 (abs) & 0.017 & 0.006 & 0.053 & & & - & & \\
\hline \multirow[t]{2}{*}{ EUS-GE } & & 0.040 & 0.018 & 0.087 & & & & & \\
\hline & & & & & -1.00 & -0.50 & 0.00 & 0.50 & 1.00 \\
\hline
\end{tabular}

There are several limitations to this study, most of which are inherent to any meta-analysis. First and foremost, three of the included studies in our analysis were published only as abstracts. While the outcomes of interest for the purposes of meta-analysis were clearly reported in these studies, details about patient characteristics, technique used and procedural outcomes were limited. We attempted to contact the abstract authors to obtain further details. While we did not receive any correspondence from two authors, one author declined to share their study details. Secondly, the included studies were not entirely representative of the general population and community practice, with most studies being performed in tertiarycare referral centers by expert endoscopists. This is important because EUS-GE techniques remain unstandardized, the learning curve for EUS-GE is still unknown, and the rate of AEs in EUS-GE might be higher in novice advanced endoscopists. All the studies included in our analysis were retrospective in nature contributing to selection bias. Third, only two studies included in our analysis reported the specific EUS-GE technique that was employed. Chen et al reported that of the 30 patients undergoing EUS-GE, EUS-guided balloon-occluded gastrojejunostomy bypass (EPASS) technique was used in 22, balloon-assisted GE in six and direct EUS-GE in two patients. In the study by Ge et al, all 22 patients underwent direct EUS-GE. We were unable to analyze if one EUS-GE technique was superior to the other. In our analysis, only three studies reported on the location of obstruction $[43,46,47]$. This was duodenal bulb in $130 \mathrm{pa}-$ tients, second portion of duodenum in 190 patients and distal duodenum in 129 patients. We were unable to assess if the location of GOO had any influence of the clinical and technical success of either technique. While there was no statistically significant difference in the technical and clinical effectiveness of EUS-GE and ES, it is important to note that statistical non-significance is an indication of uncertainty and not necessarily of equivalence. We used confidence intervals to estimate the uncertainty of the difference in success and failure rates between the two approaches. Finally, our analysis has the limitation of moderate to significant heterogeneity.

\section{Conclusion}

In conclusion, EUS-GE in expert hands has comparable effectiveness and safety profile compared to ES. It is associated with a lower rate of recurrence of $\mathrm{GOO}$ and need for re-intervention when compared to ES, making it an acceptable therapeutic intervention for patients with gastric outlet obstruction. The learning curve for EUS-GE will need to further evolve before it can be used as first line therapy in patients with GOO. Further prospective randomized controlled trials are needed to validate our findings.

\section{Acknowledgement}

The authors thank Dana Gerberi, MLIS, Librarian, Mayo Clinic Libraries, for help with the systematic literature search.

\section{Competing interests}

Dr. Adler is a consultant for Boston Scientific

References

[1] Del Piano M, Ballarè M, Montino $F$ et al. Endoscopy or surgery for malignant Gl outlet obstruction? Gastrointest Endosc 2005; 61: 421-426

[2] Pinto Pabón IT, Díaz LP, Ruiz De Adana JC et al. Gastric and duodenal stents: follow-up and complications. Cardiovasc Intervent Radiol 2001; 24: 147-153

[3] Warshaw AL, Fernández-del Castillo C. Pancreatic carcinoma. N Engl ] Med 1992; 326: 455-465 
[4] Fukami N, Anderson MA, Khan K et al. The role of endoscopy in gastroduodenal obstruction and gastroparesis. Gastrointest Endosc 2011; 74: 13-21

[5] Itoi T, Baron TH, Khashab MA et al. Technical review of endoscopic ultrasonography-guided gastroenterostomy in 2017. Digestive Endoscopy 2017; 29: 495-502

[6] Maetani I, Tada T, Ukita T et al. Comparison of duodenal stent placement with surgical gastrojejunostomy for palliation in patients with duodenal obstructions caused by pancreaticobiliary malignancies. Endoscopy 2004; 36: 73-78

[7] Takeno A, Takiguchi S, Fujita J et al. Clinical outcome and indications for palliative gastrojejunostomy in unresectable advanced gastric cancer: multi-institutional retrospective analysis. Ann Surg Oncol 2013; 20: 3527-3533

[8] van der Schelling GP, van den Bosch RP, Klinkenbij JH et al. Is there a place for gastroenterostomy in patients with advanced cancer of the head of the pancreas? World J Surg 1993; 17: 128-132; discussion 132-123

[9] Weaver DW, Wiencek RG, Bouwman DL et al. Gastrojejunostomy: is it helpful for patients with pancreatic cancer? Surgery 1987; 102: 608613

[10] Wong YT, Brams DM, Munson L et al. Gastric outlet obstruction secondary to pancreatic cancer: surgical vs endoscopic palliation. Surg Endosc 2002; 16: 310-312

[11] Yim HB, Jacobson BC, Saltzman JR et al. Clinical outcome of the use of enteral stents for palliation of patients with malignant upper $\mathrm{Gl}$ obstruction. Gastrointest Endosc 2001; 53: 329-332

[12] Hosono S, Ohtani $\mathrm{H}$, Arimoto $\mathrm{Y}$ et al. Endoscopic stenting versus surgical gastroenterostomy for palliation of malignant gastroduodenal obstruction: a meta-analysis. J Gastroenterol 2007; 42: 283-290

[13] Irani S, Baron TH, Itoi T et al. Endoscopic gastroenterostomy: techniques and review. Curr Opin Gastroenterol 2017; 33: 320-329

[14] Jeurnink SM, Steyerberg EW, van Eijck CH et al. [Gastrojejunostomy versus endoscopic stent placement as palliative treatment for a malignant constriction of the duodenum: the SUSTENT-study]. Ned Tijdschr Geneeskd 2006; 150: 2270-2272

[15] Jeurnink SM, Steyerberg EW, Hof G et al. Gastrojejunostomy versus stent placement in patients with malignant gastric outlet obstruction: a comparison in 95 patients. J Surg Oncol 2007; 96: 389-396

[16] Duan B, Guo J, Ge N et al. Preliminary use of a double-flanged, fully covered, self-expandable, metal stent with cautery in endoscopic ultrasound-guided gastroenterostomy. Endoscopy 2018; 50: E29-E31

[17] Mahler MA, Prieto RG, Oria I et al. Single-session EUS-guided hepaticogastrostomy and dual-scope gastroenterostomy: a modified technique for palliative double endoscopic biliary and gastric bypass. Endoscopy 2018; 50: 78-79

[18] Hu J, Zhang K, Sun S. Endoscopic ultrasound-guided retrievable puncture anchor-assisted gastroenterostomy. Digest Endosc 2019; 31: e11-e12

[19] Kerdsirichairat T, Irani S, Yang J et al. Durability and long-term outcomes of direct EUS-guided gastroenterostomy using lumen-apposing metal stents for gastric outlet obstruction. Endosc Int Open 2019; 7: E144-E150

[20] Sakamoto Y, Hijioka S, Maruki Y et al. Endoscopic ultrasound-guided gastroenterostomy using a metal stent for the treatment of afferent loop syndrome. Endoscopy 2019; 51: E153-E155

[21] Moher D, Liberati A, Tetzlaff J et al. Preferred reporting items for systematic reviews and meta-analyses: The prisma statement. Annals Intern Med 2009; 151: 264-269

[22] Stroup DF, Berlin JA, Morton SC et al. Meta-analysis of observational studies in epidemiology: a proposal for reporting. Meta-analysis Of Observational Studies in Epidemiology (MOOSE) group. . JAMA 2000; 283: 2008-2012
[23] Chen YI, James TW, Agarwal A et al. EUS-guided gastroenterostomy in management of benign gastric outlet obstruction. Endosc Int Open 2018; 6: E363-E368

[24] Kerdsirichairat T, Yang J, Gutierrez OIB et al. Long-term outcomes of endoscopic ultrasound-guided gastroenterostomy using lumen-apposing metal stents for gastric outlet obstruction: A 4-year cohort. Gastrointest Endosc 2018; 87: AB320-AB321

[25] Khashab MA, Kumbhari V, Grimm IS et al. EUS-guided gastroenterostomy: the first U.S. clinical experience (with video). Gastrointest Endosc 2015; 82: 932-938

[26] Tyberg A, Perez-Miranda M, Sanchez-Ocana R et al. Endoscopic ultrasound-guided gastrojejunostomy with a lumen-apposing metal stent: a multicenter, international experience. Endosc Int Open 2016; 4: E276-E281

[27] Itoi T, Ishii K, Ikeuchi $\mathrm{N}$ et al. Prospective evaluation of endoscopic ultrasonography-guided double-balloon-occluded gastrojejunostomy bypass (EPASS) for malignant gastric outlet obstruction. Gut 2016; 65: 193-195

[28] Chen YI, Kunda R, Storm AC et al. EUS-guided gastroenterostomy: a multicenter study comparing the direct and balloon-assisted techniques. Gastrointest Endosc 2018; 87: 1215-1221

[29] Barthet M, Binmoeller KF, Vanbiervliet G et al. Natural orifice transluminal endoscopic surgery gastroenterostomy with a biflanged lumen-apposing stent: First clinical experience (with videos). Gastrointest Endosc 2015; 81: 215-218

[30] Ngamruengphong S, Kumbhari V, Tieu AH et al. A novel "balloon/ snare apparatus" technique to facilitate easy creation of fistula tract during EUS-guided gastroenterostomy (EUS-GE). Gastrointest EndosC 2016; 83: AB636

[31] Khashab MA, Bukhari M, Baron TH et al. International multicenter comparative trial of endoscopic ultrasonography-guided gastroenterostomy versus surgical gastrojejunostomy for the treatment of malignant gastric outlet obstruction. Endosc Int Open 2017; 5: E275E281

[32] Perez-Miranda M, Tyberg A, Poletto D et al. EUS-guided Gastrojejunostomy Versus Laparoscopic Gastrojejunostomy: An International Collaborative Study. J Clin Gastroenterol 2017; 51: 896-899

[33] Bondi G, Bazarbashi AN, Abbas AM et al. Endoscopic gastroenterostomy versus surgical gastrojejunostomy for the treatment of gastric outlet obstruction in patients with peritoneal carcinomatosis: a retrospective comparative study. Gastrointest Endosc 2020; 91: AB303

[34] Stang A. Critical evaluation of the Newcastle-Ottawa scale for the assessment of the quality of nonrandomized studies in meta-analyses. Eur J Epidemiol 2010; 25: 603-605

[35] Cotton PB, Eisen GM, Aabakken L et al. A lexicon for endoscopic adverse events: report of an ASGE workshop. Gastrointest Endosc 2010; 71: $446-454$

[36] DerSimonian R, Laird N. Meta-analysis in clinical trials. Control Clin Trials 1986; 7: 177-188

[37] Sutton A JAK, Jones DR et al. Methods for meta-analysis in medical research. New York: J. Wiley; 2000

[38] Mohan BP, Adler DG. Heterogeneity in systematic review and metaanalysis: how to read between the numbers. Gastrointest Endosc 2019; 89: 902-903

[39] Higgins JP, Thompson SG, Spiegelhalter DJ. A re-evaluation of random-effects meta-analysis. J R Stat Soc Ser A Stat Soc 2009; 172: 137-159

[40] Higgins JP, Thompson SG, Deeks JJ et al. Measuring inconsistency in meta-analyses. BMJ 2003; 327: 557-560

[41] Duval S, Tweedie R. Trim and fill: a simple funnel-plot-based method of testing and adjusting for publication bias in meta-analysis. Biometrics 2000; 56: 455-463 
[42] Rothstein HR, Sutton A], Borenstein M. Publication bias in meta-analysis: Prevention, assessment and adjustments. John Wiley \& Sons; 2006

[43] Ge PS, Young JY, Dong W et al. EUS-guided gastroenterostomy versus enteral stent placement for palliation of malignant gastric outlet obstruction. Surg Endosc 2019; 33: 3404-3411

[44] Chen YI, Itoi T, Baron TH et al. EUS-guided gastroenterostomy is comparable to enteral stenting with fewer re-interventions in malignant gastric outlet obstruction (vol 31, pg 2946, 2017). Surg Endosc Other Intervent Tec 2017; 31: 3765-3765

[45] Iqbal U, Berger A, Confer B et al. Endoscopic ultrasound-guided gastroenterostomy vs enteral stenting for treatment of gastric outlet obstruction: A retrospective review. Am J Gastroenterol 2019; 114: S536-S537

[46] Marya N, Jaruvongvanich V, Abu Dayyeh BK et al. A multicenter international study comparing clinical outcomes of EUS-guided gastrojejunostomy, surgical gastrojejunostomy, and enteral stenting for patients with gastric outlet obstruction. Gastrointest Endosc 2020; 91: AB302-AB303

[47] Vazquez-Sequeiros E, Sanchez-Aldehuelo R, de Santiago ER et al. Endoscopic Ultrasound-Guided Gastrojejunostomy Is Superior to Duodenal Self Expandable Metal Stent for Pallitaive Treatment of Malignant Gastric Outlet Obstructtion: A Comparative Case Control Study. Gastrointestinal Endoscopy 2020; 91: AB312-AB313

[48] Chen YI, Itoi T, Baron TH et al. EUS-guided gastroenterostomy is comparable to enteral stenting with fewer re-interventions in malignant gastric outlet obstruction. Surgical Endoscopy 2017; 31: 29462952

[49] Topazian M, Ring E, Grendell J. Palliation of obstructing gastric cancer with steel mesh, self-expanding endoprostheses. Gastrointest Endosc 1992; 38: 58-60
[50] van Halsema EE, Rauws EA, Fockens P et al. Self-expandable metal stents for malignant gastric outlet obstruction: A pooled analysis of prospective literature. World J Gastroenterol 2015; 21: 12468-12481

[51] Gaidos JK, Draganov PV. Treatment of malignant gastric outlet obstruction with endoscopically placed self-expandable metal stents. World J Gastroenterol 2009; 15: 4365-4371

[52] Zheng B, Wang X, Ma B et al. Endoscopic stenting versus gastrojejunostomy for palliation of malignant gastric outlet obstruction. Dig Endosc 2012; 24: 71-78

[53] Mehta S, Hindmarsh A, Cheong E et al. Prospective randomized trial of laparoscopic gastrojejunostomy versus duodenal stenting for malignant gastric outflow obstruction. Surg Endosc 2006; 20: 239-242

[54] Fiori E, Lamazza A, Volpino P et al. Palliative management of malignant antro-pyloric strictures Gastroenterostomy vs. endoscopic stenting. A randomized prospective trial. Anticancer Res 2004; 24: 269-271

[55] Iqbal U, Khara HS, Hu Y et al. EUS-guided gastroenterostomy for the management of gastric outlet obstruction: A systematic review and meta-analysis. Endoscopic Ultrasound 2020; 9: 16-23

[56] McCarty TR, Garg R, Thompson CC et al. Effectiveness and safety of EUS-guided gastroenterostomy for benign and malignant gastric outlet obstruction: a systematic review and meta-analysis. Endosc Int Open 2019; 7: E1474-E1482

[57] Fan W, Tan S, Wang J et al. Clinical outcomes of endoscopic ultrasound-guided gastroenterostomy for gastric outlet obstruction: a systematic review and meta-analysis. Minim Invasive Ther Allied Technol 2020: 1-9 